\title{
FORECASTING ECONOMIC PERFORMANCE OF IMPLEMENTED INNOVATION OPENNESS
}

\author{
Kristina Risom Jespersen \\ Department of Economics and Business \\ Aarhus University \\ DENMARK
}

\begin{abstract}
The early stage of open innovation diffusion also hinders the use of traditional research methods in business economics. A suitable research method though relatively new in business management research is agent-based modeled simulations (ABMS). The aim of the paper is therefore also to develop an open innovation ABMS to explore the relative effects of innovation openness and initial capability endowment on firm innovation economics in a competitive context. In this respect the ABMS is applied as a data generating methodology of organizational behavior and industry dynamics. The ABMS acts as a combination of digital role play and experimental design. It is found that design and use of ABMS contribute to enlargement and testing of the usefulness and applicability of ABMS in social science.
\end{abstract}

\section{INTRODUCTION}

Open innovation research has provided valuable insights on user involvement (von Hippel 1988; Brockhoff 2003; Enkel et al. 2005; Chesbrough and Appelyard 2007; Jespersen 2010), open innovation tools (Dahan and Hauser 2002; Nambisan 2002; Namwoo and Pae 2007; Jespersen 2008; Huizingh 2011) and open innovation process design (Grönlund et al. 2010; Igartua et al. 2010). Yet, Open innovation researchers stress that companies are still early adaptors applying open innovation (Chesbrough and Crowther 2006; Knudsen and Mortensen 2011). Examples are that Starbucks, Adidas, Novo Nordisk, Doritos, Lego and P\&G apply different forms of innovation openness, whereas Nokia, Apple and Nintendo perform well without innovation openness. Consequently, the cases of success in open innovation leave little consistent guidance for other companies seeking to implement openness through user involvement in the innovation process. It is not possible to determine whether companies choosing user involvement in their innovative processes are gaining a competitive advantage in their markets (Hargadon 2002; Emden et al. 2006; Chesbrough and Appelyard 2007; Grönlund et al. 2010). The early stage of diffusion means that research has not addressed economic performance of the form of open innovation that companies may implement. The purpose of this research project is to investigate the competitive advantage generated by open innovation strategies in mild versus intensive user involving industries. The addressed research question is whether co-created knowledge and innovativeness are determinants of market performance. Especially the roles of external and internal knowledge capabilities as well as involvement strategy are investigated.

The early stage of open innovation diffusion also hinders the use of traditional research methods in business economics. A suitable research method though relatively new in business management research is agent-based modeled simulations (ABMS) (Bhuiyan et al. 2004; Pajares et al. 2004; Ma and Nakamori 2005; Voges and Pope 2006). The aim of the paper is therefore also to develop an open innovation ABMS to explore the relative effects of innovation openness and initial capability endowment on firm innovation economics in a competitive context. In this respect the ABMS is applied as a data 
generating methodology of organizational behavior and industry dynamics. The ABMS acts as a combination of digital role play and experimental design. It is found that design and use of ABMS contribute to enlargement and testing of the usefulness and applicability of ABMS in social science.

The structure of the paper is as follows. First, the theoretical background is presented so as to outline the pre-requisites build into the simulation design. Second, the designed simulation and its agents are given together with behavioral assumptions and calculations. Third, the analyses and results are discussed and a conclusion put forward.

\section{THEORETICAL BACKGROUND}

A company's innovation characteristics can be defined by the sum of external and internal knowledge capabilities (March 1991). These capabilities for information processing determine the innovativeness of the output from the development process (Moorman 1995). From open innovation research three prerequisites of open innovation can be derived (Chesbrough and Crowther 2006; Dodgson et al. 2006; Emden et al. 2006; Laursen and Salter 2006; Chesbrough and Appelyard 2007; Enkel et al. 2009; Gassmann et al. 2010; Jespersen 2010). These are a company's external knowledge capabilities, specifying how well and how much knowledge is generated and disseminated from users (Katila and Ahuja 2002; Laursen and Salter 2006) (Appelyard 2003; Emden, Calantone et al. 2006; Chesbrough and Appelyard 2007). The involvement strategy conceptualized as the sequence of user involvement determines when users are invited to collaborate (Fuchs and Schreier 2011; Jespersen 2011; Nambisan 2002). And the internal knowledge capabilities of a company are determined by the level of exploitation and the quality of internal knowledge held by the organization (Gupta et al. 2006).

These pre-requisites of open innovation are found to positively influence knowledge co-creation between company and users in the innovation process as well as to increase the innovativeness of innovative output. Both knowledge co-creation and innovativeness are expected to generate higher sales in the market, and as such companies with these knowledge capabilities and user empowerment would gain a competitive advantage in their industry. External knowledge capabilities and involvement strategy are both elaborated on in the following sections.

\subsection{External Knowledge Capabilities}

A company's external knowledge capabilities establish how well and how much knowledge is generated and disseminated from users (Gupta et al. 2006). It is co-development of new products through a balance of value capture (knowledge pooling) and value creation (innovation) (Appelyard 2003; Emden et al. 2006; Chesbrough and Appelyard 2007). The recognition of the value of information from a user can be defined as the exploration and absorption characterizing the company (Zahra and George 2002; Kasdan et al. 2004). The external search process consists of breath and depth of external sources worked into innovative activities (Katila and Ahuja 2002; Laursen and Salter 2006). It represents the invitation to collaborate communicated to users. Absorption is conceptualized as the capability to understand and extract useful knowledge form users' input to innovation (Nooteboom et al. 2007). Furthermore, the company would place weight on either technological knowledge (WTK) or use experience (WUE) information elements given by users responding to the invitation to participate in innovation. Company weights defined by the company history of market pull or technology push in their innovative efforts (Rosenkopf and Nerkar 2001; Hargadon 2002; Nambisan 2002).

\subsection{Involvement Strategies}

Users can take on three different roles in the innovation process measured on two empowerment dimensions: i) the power to submit ideas and ii) the power to select designs. Each role has a place in the NPD process that is most beneficial to new product projects (Nambisan 2002; Fuchs and Schreier 2011). The first role users may have in NPD is that of advisor. In this role users act as information suppliers of positive and negative feedback as well as of suggestions for improvements of existing products or of new product ideas (Brockhoff 2003; Janssen and Dankbaar 2008; Kim and Bae 2008). The second role of us- 
ers is that of selecting designs, types or versions to be marketed. In this role users are given the power to 'vote' among alternatives (Fuchs and Schreier, 2011). This is the traditional user roles of evaluation, testing and debugging in the last part of the NPD process (Magnusson, 2009). Users have a sign-off responsibility (Brockhoff, 2003). The third role of users is as team member. In this role users are a source of innovation related knowledge (Bogers et al. 2010). Online channels enabling users to experiment and innovate are, for example, user communities, simulations, and virtual product testing (Dahan and Hauser 2002; von Hippel and Katz 2002). Companies may choose to involve users in some or all stages of the innovation process (Brockhoff 2003; Enkel et al. 2005). The sequence of user involvement determines when users are invited to collaborate (Fuchs and Schreier 2011; Jespersen 2011). For example, companies $\mathrm{A}$ and $\mathrm{B}$ involves users in idea generation. Company $\mathrm{C}$ involves users in the development stage. Company $\mathrm{D}$ involves users in idea generation and testing, whereas company $\mathrm{E}$ has users involved in all stages. Company $\mathrm{G}$ does not involve any users. With three user roles and three development stages the possible user involvement sequences that companies may pursue are calculated as the k-combinations for all $\mathrm{k}$ expressed by $2^{3}$, including the no involvement strategy equaling eight combinations of user involvement in the innovation process.

\section{AGENT-BASED SOCIAL SIMUALTION}

The paper forecasts the economic performance of the implemented innovation openness. The agent-based simulation tool 'Repast' is used to generate data (North and Macal 2007; Coen and Maritan 2011). We created a model with eight companies (see 2.2) and 1000 users (see table x1) and repeated it six times for mild and intensive open innovation industries, respectively. In model 1 innovation performance for companies in a mild open innovation industry was observed. The industry was defined as mild based on their level of external orientation which were restricted to the interval [0; 0.5]. All other company characteristics were set randomly in the interval [0;1]. Hence, in a mild open innovation industry not all companies perform open innovation through user involvement. In model 2 innovation performance for companies in an intensive open innovation industry was observed. The industry was defined as intensive based on its level of external orientation which was set to the interval $[0.5 ; 1]$. All other company characteristics were set randomly in the interval [0;1]. Similar, in the intensive open innovation industry all competitors had an above average level of open innovation. Figure 1 presents the designed ABSS model. Each agent type is represented by a box in which the first field gives the agent type. The second field shows the data held by the agent, and the third field gives agent behavior. Arrows show the flow of information between the agents. All agents are embedded in a world object which control the time steps. There are four time steps, three development stages, and a market step.

\subsection{User Agents Modeled}

The quality of incoming knowledge from users depends on their use experience and technical domain knowledge levels. Innovation literature conceptualizes five different types of users with different knowledge capabilities for NPD. These five types are requesting, pioneering, first-buyer, launching, and lead users (Enkel et al. 2005; Jespersen 2010). Users may possess knowledge in the application domain and knowledge in the technology domain of the product (Enkel et al. 2005; Magnusson 2009; Jespersen 2010; Jespersen 2011). In addition to knowledge, the motivation of users to collaborate with companies to participate in innovation is important (Lettl 2007). However motivation is not contingent on user type. Though lead users are the most innovative and the first-buyer the least innovative, the likelihood of users responding to an invitation to participate in innovation from a company is assumed almost random as factors like solicited vs. unsolicited involvement and previous relationship with company among others also determine users willingness to engage. Table 1 show the programmed variables characterizing users as well as their distribution in the simulation. 
Risom Jespersen

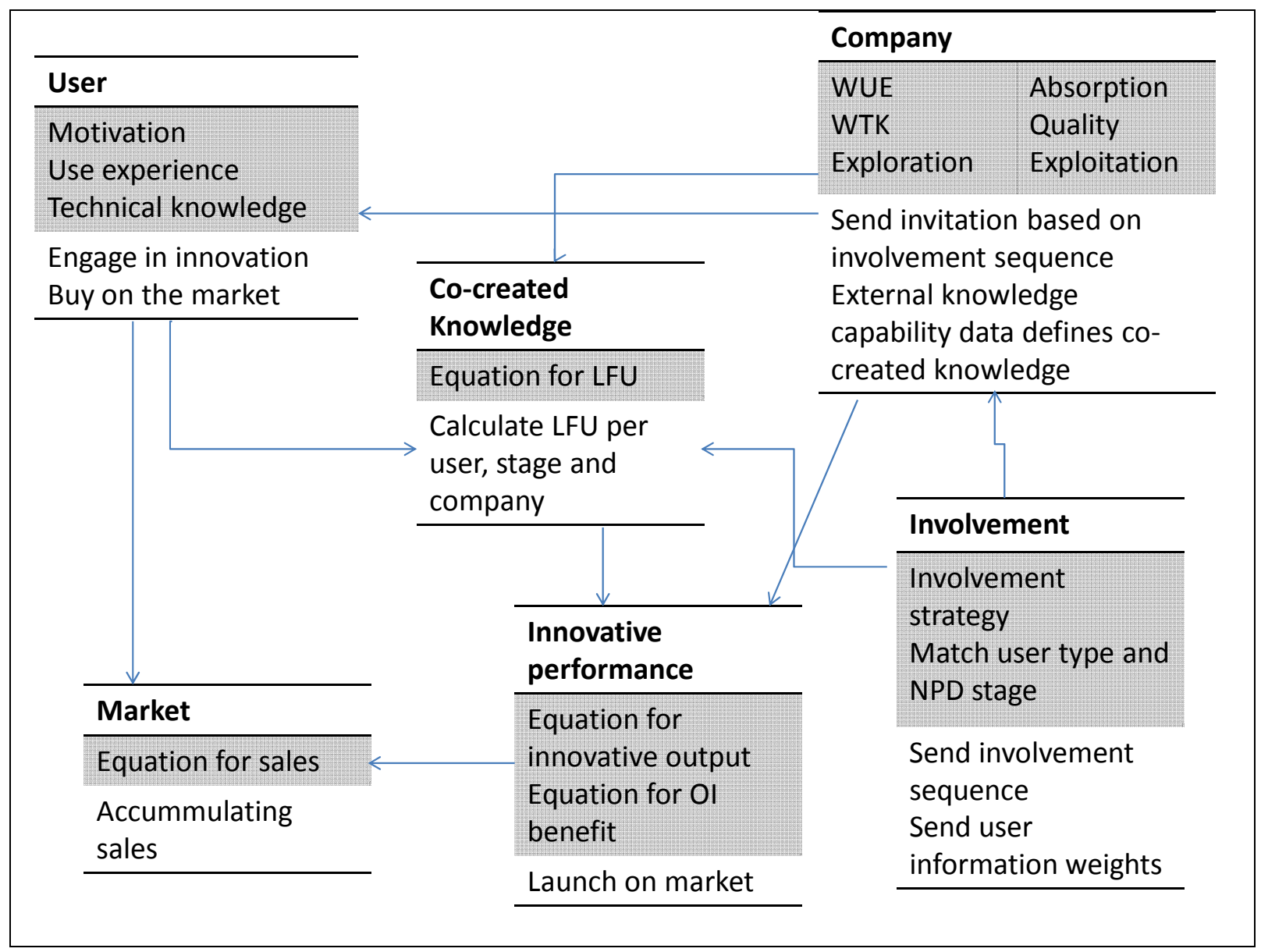

Figure 1: A schematic presentation of the agent-based social simulation

Table 1: Modeled user characteristics

\begin{tabular}{|l|c|c|c|c|c|}
\hline & Lead user & Hobby expert & Pioneer & Requesting user & First-buyer \\
\hline Use experience (UE) & {$[0.8 ; 1]$} & {$[0 ; 0.5]$} & {$[0.5 ; 1.0]$} & {$[0 ; 1]$} & {$[0 ; 0.2]$} \\
\hline $\begin{array}{l}\text { Technical knowledge } \\
\text { (TK) }\end{array}$ & {$[0.8 ; 1]$} & {$[0.5 ; 1]$} & {$[0.2 ; 0.5]$} & $0 ; 0.2]$ & {$[0 ; 0.2]$} \\
\hline $\begin{array}{l}\text { Distribution in } \\
\text { population }\end{array}$ & $5 \%$ & $15 \%$ & $20 \%$ & $50 \%$ & $10 \%$ \\
\hline $\begin{array}{l}\text { Motivation to } \\
\text { innovation }\end{array}$ & Random [0;1] & Random [0;1] & Random [0;1] & Random [0;1] & Random [0;1] \\
\hline
\end{tabular}

\subsection{Knowledge Co-creation}

The first step of the knowledge co-creation is that users and company interact. The companies sent out invitations to collaborate in the development process, and users respond to these. The proposition held in this paper is that the open innovation paradigm builds on co-creation of knowledge between companies and users to form innovative output (Chesbrough and Crowther 2006; Chesbrough and Appelyard 2007). 
Companies and users bring knowledge to the open innovation process. The rule for users' choice of company to engage within the simulation was based on Euclidean one dimension distance. The gap between the invitation to be involved send by the company (the company level of exploration) and the motivation to innovate held by the user. The assumption is that a user would respond to the invitation to which the distance between users' motivation to innovate and the innovation of invitation send by companies is minimized. Hence:

$$
\text { Collaboration }_{\mathrm{njk}}=\operatorname{Min}_{\mathrm{njk}}\left(\mid \text { motivation }_{\mathrm{nj}}-\text { invitation }_{\mathrm{kj}} \mid\right)
$$

Where $\mathrm{i}=$ user type of user $\mathrm{n}$ in sample, $\mathrm{n}=$ user in sample, $\mathrm{k}=$ company and $\mathrm{j}=$ stage of involvement. The same interaction principle was assumed to be valid for sales. Users are assumed to buy products that minimizes the gap of innovation between user and product (company).

When users find a company to collaborate with, their knowledge is pooled together with company knowledge. The knowledge co-creation was calculated as the interaction of the modeled characteristics of company and user. In addition, research on user involvement in NPD has found that it is important for the innovative output that companies involve users capable of providing input to the NPD stage in question (Enkel et al. 2005). A clear distinction exists between stages and relevant types of users to involve (Jespersen 2010). In other words, research finds that the match between user type and development stage is significant for the resulting innovative output accomplished by an open innovation strategy. The findings from research can be converted into an impact factor of information from users in the different stages of the NPD process. The impact factor of user knowledge was modeled to vary from very positive to very negative for each of the five user types in the three development stages simulated. As such, knowledge co-creation with each user and for each development stage by a company was calculated as:

$$
\begin{aligned}
& \text { KC-Cuser }_{\text {stage }}=((\text { WUE*UserExp })+(\text { WTK*TechKnowledge })) * \text { exploration*absorption*Stage } \text { user.know.impact } \\
& \mathrm{KC} \text {-Ccompany } \text { stage }_{\text {s }}=\Sigma\left(\text { KC-Cuser }_{\text {stage }}\right) ; \text { stage }=\{\text { idea, development, test }\}
\end{aligned}
$$

\subsection{Innovation Performance}

After three time steps in the simulation, knowledge co-creation over a new product is ready to be launched on the market. Innovation performance was modeled pre-launch and post-launch. The prelaunch measurement of innovation output performance is innovativeness. Innovativeness of output was calculated in the simulation as the sum of co-created knowledge across the development stages and a company's internal knowledge:

$$
\text { Innovativeness }=\left(\mathrm{LN}\left(\Sigma\left(\mathrm{KC}-\text { Ccompany }_{\text {stage }}\right)\right)+3 *(\text { CompanyExploitation*CompanyQuality })\right) / \mathrm{k}
$$

This innovativeness measurement was then acting as the launch invitation to users in the fourth step of the simulation. Hence, based on the match of a company's innovativeness with users, motivation towards innovation sales was determined. Sales were measured as the number of users choosing to move to each of the companies in step four of the simulation. Sales were therefore the post-launch measurement of innovation performance in the simulation.

\subsection{Analysis}

Hierarchical regression models were applied to forecast economic performance of open innovation in the two modeled industries. Company pre-requisites were the independent variables in the analyses of determinants of co-created knowledge, innovativeness and sales. Results for each type of industry are shown in table 2 and 3. 
Table 2: Mild open innovation industry

\begin{tabular}{|c|c|c|c|c|c|c|}
\hline & $V C \mathrm{C}$ & & reness & & Sales & \\
\hline & $\Lambda C-C$ & Model 1 & Model 2 & Model 1 & Model 2 & Model 3 \\
\hline Exploration & $.410 * * *$ & $.346 * *$ & .074 & $.276 *$ & .157 & .119 \\
\hline Internal knowledge & $.207 *$ & $.429 * *$ & $.292 * *$ & $.257 \mathbf{a}$ & .197 & .049 \\
\hline Empowerment & & & & & & \\
\hline Idea & $.346 * *$ & .102 & -.128 & .105 & .005 & .070 \\
\hline Development & -.008 & -.184 & $-.179 a$ & -.203 & -.201 & -.111 \\
\hline Choice & $.354 * *$ & .103 & -.132 & .037 & -.066 & .000 \\
\hline $\mathrm{KC}-\mathrm{C}$ & & & $.663 * * *$ & & .290 & -.045 \\
\hline Innovativeness & & & & & & $.507 *$ \\
\hline $\mathrm{R}^{2}$ & .564 & .413 & .605 & .222 & .258 & .360 \\
\hline$\Delta \mathrm{R}^{2}$ & & & $.192 * * *$ & & .037 & $.101 *$ \\
\hline
\end{tabular}

Table 3: Intensive open innovation industry

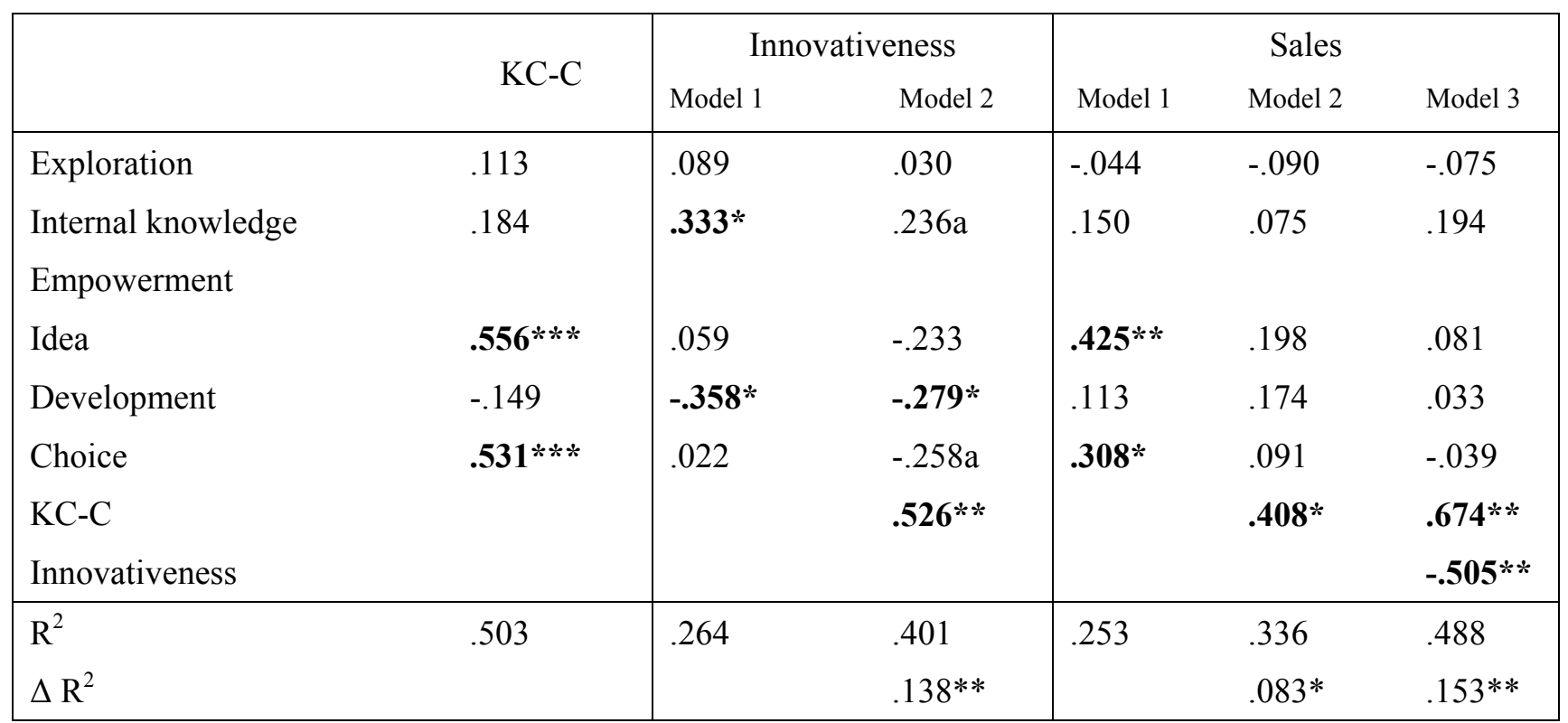

\section{RESULTS}

\subsection{Knowledge Co-creation}

Knowledge co-creation concerns companies' learning from users. The results show a difference between mild and intensive industries. Exploration in combination with internal knowledge forms ambidexterity. 
This ambidexterity is significant for companies' ability to co-create knowledge with users in mild industries. Neither is significant for companies learning from users in intensive industries. Investigating learning from users further, regression analysis on simulation data shows that in mild industries learning builds on pioneering users $(\beta=1.022)$, requesting users $(\beta=.262)$ and hobby experts $(\beta=.215)$. Differently, lead users $(\beta=.710)$ and requesting users $(\beta=.818)$ dominate company learning in intensive industries. In both industries idea and choice empowerment are involvement strategies that contribute positively to knowledge co-creating. Especially in intensive industries it seems a mandatory activity to perform.

\subsection{Innovativeness}

The results on pre-launch performance demonstrate significant differences between mild and intensive open innovation industries. For mild industries, companies' innovativeness is driven by co-created knowledge. The ability to learn from users fully mediates the positive effect of a company's exploration and lowers the contribution of internal knowledge to innovative output. Hence, in a mild industry it is about learning from users more than how much you invite them to collaborate. Nintendo's development of the Wii video game console is incongruent with this finding. In an intensive open innovation industry, internal knowledge is fully mediated by co-created knowledge. Furthermore, the empowerment of users in the development stage is found to reduce innovativeness. An explanation may be that co-created knowledge stems from requesting users. Research finds that requesting users destroy innovative efforts if involved in the development stage (Jespersen 2010). Knowledge co-creation is a challenge to master.

\subsection{Sales}

Open innovation does give companies a competitive advantage. The findings emerging from table 2 and 3 regarding a mild industry are that innovativeness influences sales positively and fully mediates the effects from external knowledge capabilities, involvement strategy, and internal knowledge capabilities. In an intensive open innovation industry, innovativeness and knowledge co-creation fully mediates the effects from external knowledge capabilities, involvement strategy, and internal knowledge capabilities. Interestingly, the effected of innovativeness on sales is negative. Competing in an intensive open innovation industry may result in company over-invention relative to the market. Hence competing on innovativeness becomes an innovative capability trap. Market alignment is ensured by knowledge co-creation. This may explain why companies in intensive markets learn from requesting users.

\section{CONCLUSION}

The purpose of the paper was to explore how companies gain competitive advantages with open innovation. The drives vary with the industry level of 'invitation to collaborate'. The implications for managers are that exploration, indentifying pioneering users and ensuring innovativeness, gives a competitive advantage in mild industries. In intensive open innovation industries, a competitive advantage is created through involvement of lead users and requesting users with attention to innovation-market alignment.

Methodologically, the conclusion is that agent based simulations hold great potential as organizational behavior simulators. ABMS applied as demonstrated in this paper extend previous use of this research methodology.

\section{REFERENCES}

Appelyard, M. M. 2003. "The influence of knowledge accumulation on buyer-supplier codevelopment projects." Journal of Product Innovation Management 20: 356-373.

Bhuiyan, N., D. Gewin and V. Thomson. 2004. "Simulation of the new product development process for performance improvement." Management science 50(12): 1690-1703.

Bogers, M., A. Afuah and B. Bastian. 2010. "Users as innovators: A review, critique, and future research directions." Journal of Management 36(4): 857-875. 
Brockhoff, K. 2003. "Customers' perspectives of involvement in new product development." International Journal of Technology Management 26(5): 464-481.

Chesbrough, H. and A. K. Crowther. 2006. "Beyond high tech: early adopters of open innovation in other industries." R\&D Management 36(3): 229-236.

Chesbrough, H. W. and M. M. Appelyard. 2007. "Open innovation and strategy." California Management Review 50(1): 57-76.

Coen, C. A. and C. A. Maritan. 2011. "Investing in capabilities: The dynamics of resource allocation." Organization Science 22(1): 99-117.

Dahan, E. and J. R. Hauser. 2002. "The Virtual Customer." Journal of Product Innovation Management 19: 332-353.

Dodgson, M., D. Gann and A. Salter. 2006. "The role of technology in the shift towards open innovation: The case of Procter \& Gamble." R\&D management 36(3): 333-346.

Emden, Z., R. J. Calantone and C. Droge. 2006. "Collaborating for new product development. Selecting the partner with maximum potential to create value." Journal of Product Innovation Management 23: 330-341.

Enkel, E., O. Gassmann and H. W. Chesbrough. 2009. "Open R\&D and open innovation: Exploring the phenomenon." R\&D management 39(4): 311-316.

Enkel, E., J. Perez-Freije and O. Gassmann. 2005. "Minimizing Market Risks Through Customer Integration in New Product Development: Learning from practice." Creativity and Innovation Management 14(4): 425-437.

Fuchs, C. and M. Schreier. 2011. "Customer empowerment in new product development." Journal of Product Innovation Management 28: 17-32.

Gassmann, O., E. Enkel and H. Chesbrough. 2010. "The future of open innovation." R\&D Management 40(3): 213-221.

Grönlund, J., D. R. Sjödin and J. Frishammar. 2010. "Open innovation and the stage-gate process." California Management Review 52(3): 106-131.

Gupta, A. K., K. G. Smith and C. E. Shalley. 2006. "The interplay between exploration and exploitation." Academy of Management Journal 49(4): 693-706.

Hargadon, A. B.. 2002. "Brokering Knowledge: Linking learning and innovation." Organizational Behavior 24: 41-85.

Huizingh, E. K. R. E. 2011. "Open innovation: state of the art and future perspectives." Technovation 31: 2-9.

Igartua, J. I., J. A. Garrigós and J. L. Hervas-Oliver. 2010. "How innovation management techniques support an open innovation strategy." Research \& Technology Management May-June: 41-52.

Janssen, K. L. and B. Dankbaar. 2008. "Proactive involvement of consumers in innovation: Selecting appropriate techniques." International Journal of Innovation Management 12(3): 511-541.

Jespersen, K. R.. 2008. User-driven product development: Creating a user-involving culture. Denmark, Forlaget Samfundslitteratur.

Jespersen, K. R. 2010. "User-involvement and open innovation: The case of decision-maker openess." International Journal of Innovation Management 14(3): 471-489.

Jespersen, K. R. 2011. "Online Channels and Innovation: Are users being empowered and involved?." International Journal of Innovation Management 15(6): 1-19.

Kasdan, T. B., P. Rose and F. D. Fincham. 2004. "Curiosity and exploration: Facilitating positive subjective experiences and personal growth opportunities." Journal of Personality Assessement 82(3): 291305.

Katila, R. and G. Ahuja. 2002. "Something old, Something new: A longitudinal study of search behavior and new product introduction." Academy of Management Journal 45(6): 1183-1194.

Kim, J. H. and Z.-T. Bae. 2008. "The role of online brand community in new product development: Case studies on digital product manufacturers in Korea." International Journal of Innovation Management 12(3): 357-376. 
Knudsen, M. P. and T. B. Mortensen. 2011. "Some immediate - but negative - effects of openness on product development efforts." Technovation 31: 54-64.

Laursen, K. and A. Salter. 2006. "Open for innvoation: The role of openness in explaning innovation performance among U.K. manufacturing firms." Strategic Management Journal 27: 131-150.

Lettl, C.. 2007. "User Involvement Competence for Radical Innovation." Journal of Engineering and Technology Management 24: 53-75.

Ma, T. and Y. Nakamori. 2005. "Agent-based modeling on technological innovation as an evolutionary approach." European Journal of Operational Research 166: 741-755.

Magnusson, P. R. 2009. "Exploring the contributions of involving ordinary users in ideation to technology-based services." Journal of Product Innovation Management 26: 578-593.

March, J. G. 1991. "Exploration and exploitation in organizational learning." Organization Science 2(1): 71-87.

Moorman, C. 1995. "Organizational market information processes: cultural antecedents and new product outcome." Journal of Marketing Research 32(august): 318-335.

Nambisan, S.. 2002. "Designing virtual customer environments for new product development: Toward a theory." Academy of Management Review 28(3): 392-413.

Namwoo, K. and J. H. Pae. 2007. "Utilization of new technologies: Organizational adaptation to business environments." Journal of the Academy of Marketing Science 35: 259-269.

Nooteboom, B., W. V. Haverbeke, G. Duyesters, V. Gilsing and A. v. d. Oord. 2007. "Optimal cognitive distance and absorptive capacity." Research Policy 36: 1016-1034.

North, M. J. and C. M. Macal. 2007. Managing business complexity: Discovering strategic solutions with agent-based modeling and simulation. New York, Oxford University Press.

Pajares, J., C. Hernández-Inglesias and A. López-paredes. 2004. "Modelling learning and R\&D in innovative environments: A cognitive multi-agent approach." Journal of Artificial Societies and Social Simulation <http://jasss.soc.surrey.ac.uk/7/2/7.html >.

Rosenkopf, L. and A. Nerkar. 2001. "Beyond local search: Boundary spanning, exploration, and impact in the optical disk industry." Strategic Management Journal 22: 287-306.

Voges, K. E. and N. K. L. Pope, Eds.. 2006. Business applications and computational intellingence, Idea Group Publishing.

von Hippel, E. (1988). The Sources of Innovation, Oxford University Press, Inc.

von Hippel, E. and R. Katz. 2002. "Shifting innovation to users via toolkits." Management Science 48: 821-833.

Zahra, S. A. and G. George. 2002. "Absorptive capacity: A review, reconceptualization, and extension." Academy of Management Review 27(2): 185-203.

\section{AUTHOR BIOGRAPHIES}

KRISTINA RISOM JESPERSEN is an Associate Professor in the Department of Economics and Business at Aarhus University, Denmark. Her research interests include user involvement, new product development decisions making and managerial behavior in the innovation process as well as the use of simulation methods to innovations management and in particular open innovation. She is an associate reviewer of IJIM and EJIM. Her email is kjespersen@econ.au.dk. 